\title{
Novel Approaches to Early Pregnancy Detection with Decreased Mortality Rate
}

\author{
Mandheer Kaur*1, Ankit Magotra ${ }^{2}$, Shilpa ${ }^{3}$, Love Kumar ${ }^{3}$, Vikas Menon, ${ }^{3}$ Palki Sahib Kaur ${ }^{4}$ Arockia M. Babu ${ }^{5}$ \\ ${ }^{1,3,4}$ Chandigarh College of Technology, CGC Landran \\ ${ }^{2}$ Animal Genetics and Breeding, LUVAS, Hisar \\ ${ }^{5}$ Chandigarh College of Pharmacy, CGC Landran \\ *mandheer.cct@cgc.edu.in
}

Abstract - To achieve better reproductive management rapid and reliable diagnostic tools are compulsory. Quick pregnancy recognition not only reduces the calving interval but also provide timely cure of disorders and mishappenings. Cattle, the economic animal in India is well known for pregnancy losses and postpartum related difficulties. In absence of medical aids and awareness this situation is getting more prominent. Although variety of traditional methods are in practice since decades but none of them qualifies for ideal candidate for diagnosis. These methods fail on technical ground in specificity, sensitivity and accuracy. With advancement in Biotechnological applications in animal sector, a new hope for getting novel biomarkers for pregnancy diagnosis has been raised. This review attempts to highlight and compare conventional and innovative approaches to detect bovine pregnancy early with low mortality rate.

Keywords: Bovine, pregnancy, Diagnosis, Traditional methods, Novel methods

\section{INTRODUCTION}

Livestock has great impact on Indian economy. Livelihood of more than 20.5 million Indians is from animal farming. Livestock practice is also providing employment to majority of the population. 25.6 percent of agricultural GDP is generated by livestock production and management. National economy is highly dependent on sustainable and regulated practices.

The limitations faced for achieving this goal is to determine and maintain cattle biological efficiency and production. The technical issues responsible for this non-management are insufficient food, reduced strength, least probable genotype selection for breeding. In addition to these physical barriers infectious diseases and less specific diagnostic tools are also prevalent for causing animal loss as well as deteriorate economy. The need of the day is to recognize and evaluate the risk associated with production, management and commercial impact and solution for optimum bovine health [9].Fertility is a key to higher productivity in dairy cows. Loss of pregnancy is major cause of decreased fertility rate and leads to economical loss. Various factors contributing to this low rate are heat stress, less progesterone post conception etc. Effectual and rapid methods are required to develop more effective procedures and aids for competent herd reproduction. Pregnancy loss generally results in fetal membrane retention and ailments like endometritis which has further shrunken generative capabilities. Therefore this study was determined to define the downstream effects of pregnancy loss and compare traditional and novel methodologies for early pregnancy detection and cost- effective animal handling. Innovation and progression in biotechnological techniques has unwrapped.

The new horizons for research and development sector to look early biomarkers and tools in bovine pregnancy. As in cattle the embryo loss occurs at $16^{\text {th }}$ day. It has also been reported that embryo mortality results in economy loss due to prolonged diagnosis. So, highly specific and user friendly tools are the need for today to being respite of relief for farmers.
II.

\section{EMBRYO CHARACTERISTICS THROUGHOUT PREGNANCY}

The characteristics of the embryo throughout the pregnancy period have been tabulated in Table 1.

Table-1 Embryo features with respect to development stages

\begin{tabular}{|c|c|c|}
\hline & Days & Characteristics \\
\hline \multirow[t]{4}{*}{ Stage 1} & $\begin{array}{l}30-35 \\
\text { days }\end{array}$ & $\begin{array}{l}\text { vesicle filled with fluid filled vesicle cover } \\
\text { embryo. }\end{array}$ \\
\hline & 45 days & Uterus exhibit enlarged horn. \\
\hline & 60 days & Size of horn is $8-10$ inch \\
\hline & 90 days & $\begin{array}{l}\text { Bloated uterus, fetus size is } 6.5 \text { inch. } \\
\text { Detectable heart heart beat. }\end{array}$ \\
\hline Stage 2 & 120 days & $\begin{array}{l}\text { Fetus size is approximate } 10-12 \text { inches } \\
\text { long. }\end{array}$ \\
\hline Stage 3 & & $\begin{array}{l}\text { Detectable weight on the cervix. Uterus } \\
\text { shifting. }\end{array}$ \\
\hline
\end{tabular}

\section{PREGNANCY DIAGNOSIS APPROACHES}

The pregnancy diagnosis method is classified into Direct and Indirect techniques.

\section{A. Straight Methods for Pregnancy Diagnosis}

a) Rectal Palpation Method: It was discovered by Cowie for pregnancy diagnosis in cattle. It is the oldest and most widely used technique. It confirmation window is 30 days from gestation onwards [1]. It is a simple, cost effective, and widely adapted method. Disadvantage of this procedure is that it can detect accurately only after $45^{\text {th }}$ day of pregnancy and detecting pregnancy earlier by this method leads to increase in high mortality rate of embryo [3].

Advantage: Instant observations to treat non-pregnant cattle. Accuracy:

- $\quad$ Require high expertise to reach $95 \%$.

- Diagnostic window 35 and 65 days post AI. Demerits:

- Failure to withdraw the uterus

- Abnormality in uterine matters 


\section{CGCDIJCTR}

- Inappropriate examination schedule.

Safety: Although, it is commonly used exercise for pregnancy diagnosis, but unsuitable embryo injury may happen.

b) Ultrasonography: Ultrasonography has reduced the detection window on 28 days after insemination. The modulation start appearing by day 21 after breeding, it is the moment when fetal heartbeat can be confirmed. As this method is non invasive, precise and efficient for early pregnancy diagnosis so palpationinduced abortions can be avoided. A field study has revealed the sensitivity of this tool was observed to be $97.9 \%$ [2]. Similarly, the researchers have documented that sensitivity and specificity of this aid in lactating dairy cows from 28 to 35 days after AI were 97\%. Ultrasonography has proven more effective in correlation with pregnancy-specific proteins in plasma with false negative diagnosis results.

Accuracy: High accuracy helps in achieving no fertility problems. Factor that affects the efficacy are operator skills and animal restriction. When these elements are balanced then optimized results are obtained.

Table 2: Ultrasonography gravidity detection days (2)

\begin{tabular}{|l|r|c|}
\hline \multirow{2}{*}{ Characteristic } & \multicolumn{2}{|c|}{ First day detected } \\
\cline { 2 - 3 } & mean & range \\
\hline Embryo proper & 20.3 & 19 to 24 \\
\hline Heart beat & 20.9 & 19 to 24 \\
\hline Allantois & 23.2 & 22 to 25 \\
\hline Spinal cora & 29.1 & 26 to 33 \\
\hline Forelimb buds & 29.1 & 28 to 31 \\
\hline Amnion & 29.5 & 28 to 33 \\
\hline Eye orbit & 30.2 & 29 to 33 \\
\hline Hindlimb buds & 31.2 & 30 to 33 \\
\hline Placentomes & 35.2 & 33 to 38 \\
\hline Split hooves & 44.6 & 42 to 49 \\
\hline Egingl movements & 44.8 & 42 to 50 \\
\hline Ribs & 52.8 & 51 to 55 \\
\hline
\end{tabular}

B. Novel bovine pregnancy biomarkers and indicators (Indirect Methods)

a) Interferon tau and Pregnancy: Survived Corpus luteum is responsible or successful pregnancy. This is the key reason which makes early pregnancy detection mechanism most thoughtful approach embryo release specific receptors which if detected timely pregnancy loss can be minimized. Another pathway is to overcome leutolysis otherwise which end up with oestrus cycle. Interferon tau is pregnancy specific protein. In cattle it has been reported that this gene is expressed on day $12^{\text {th }}$ after insemination in trophoectoderm. As it proceed towards 15 $16^{\text {th }}$ day its level were found high [10]. This protein also modulates neutrophils and lymphocytes during these early days [21]. These reports strongly strengthen the hypothesis of interferon tau as a pregnancy biomarker in cattle. In ruminants interferon tau has also been documented for preventing leutolysis of the corpus luteum. Progesterone is compulsory for keeping corpus luteum alive and its prepare uterus for conceptus. INFT work in paracrine mechanism to block uterine prostaglandin F2 $\alpha$ which encourage leutolysis. Thus P4 and IFNT coordinate in establishment of pregnancy and gene expression during early pregnancy in the uterine endometrium in ruminanats [24].

b) OAS1 (2'-5' oligoadenylate synthetase) The IFNT has been shown to stimulate OAS1 transcripts in PBMCs in pregnant ruminants. The OAS1 expression was amplified during days 1518 in heifers and cow. A study by Shirasuna [23] revealed that OAS1 expression did not vary in pregnant and non-pregnant cows. The OAS1 mRNA expression was elevated within 24-48 $\mathrm{h}$ in PBMCs after initial signalling of IFNT in pregnant ewes $16^{\text {th }}$ day . However, OAS1 protein expression was increased on days 15 , maintained up to days 17 and then decreased on days 19 in pregnant cows [11]. Interferons produced from bovine and ovine conceptus in early pregnancy i.e. bTP-1 and oTP-1respectively, accentuates OAS1 expression in endometrium of pregnant cow and ewe. In sow, the OAS1 expression did not reveal any significant change suggesting that the maintenance of pregnancy might be independent of OAS1 gene. Higher expression of OAS1 transcript on $18^{\text {th }}$ days of gestation in buffaloes suggests that OAS1 might serve as ideal pregnancy marker [21].

c) MiRNAs: potential biomarkers for pregnancy diagnosis: Micro RNAs (miRNA) are now being targeted as a simple and available biomarkers for various diseases and physiological states. 18- 22 nucleotides these miRNAs candidate for gene expression and their detectable range has been found in biological fluids e.g serum, amniotic fluid, urine, milk etc. [12] In maternal serum, the circulating miRNA's were observed as a potential biomarkers of pregnancy, as these have considerable impact on gene expression and regulation. An increase in mi RNA has been studied by Gilad in pregnant females .Thus this finding opened the doors to identify more miRNA's that were found only during pregnancy and also among various species. In pregnant mares, pregnancy specific markers identified 7 miRNAs which were not found in non-pregnant controls. [16] Studies done on pregnant sheep confirmed miRNA presence in the uterine lumen fluid [17]. All these findings confirmed likely the role of miRNA in conceptus-endometrial interactions during the onset of pregnancy. In support of the above findings, a follow up study conducted and proved that EV's originates from trophectoderm and uterine epithelia and is involved in intercellular communication. Now the research is going on to look for miRNA's as biomarker for detetction of pregnancy in the cow. A study conducted in 2015 reported the presence of exosomal miRNAs were differentially expressed in pregnant versus non- pregnant cows [18].In an another recent study revealed that, miRNA, bta-mir 140, was identified as an early biomarker for pregnancy detection. After 13 days onwards, btamir 140 levels was up regulated in all pregnant cows and nonlactating cows but at $19^{\text {th }}$ day its level was increased in all pregnant cows [19]. Likewise findings from Ioannidis and Donadeu [20] identified 6 miRNA that were differentially expressed in pregnant heifers. Thus findings from various studies concludes that mi RNA's can be used as an effective detection tool for early pregnancy detection. In addition, miRNA also give information regarding embryonic viability. The data from various studies concludes that miRNA at day $17^{\text {th }}$ and $24^{\text {th }}$ of gestation were present in abundance when compared with cows that experience embryo mortality versus cows having successful pregnancy. Further prospects are towards more 

CGCDIJCTR

research to be done to detect exact miRNA responsible for embryo viability study and also to assess the reproducibility of all these findings done till now.

\section{CONCLUSION}

Early pregnancy recognition is pre requisite for today livestock production and management. Although estrogen and progesterone are also considered for gravidity checking and confirmation. But the problem associated with these hormones is the low levels during early days and moreover the estimation procedures are either chemical or radiolabelling (24). Further these techniques are beyond local farmer abilities. Pregnancy diagnosis needs multifaceted discipline utilising various physiological, hormonal and proteomics strategies. Conventional or traditional methods widely practiced are failing on accuracy and efficiency terms. Moreover technical personal adopting skilled palpations are very few. Already available tools are still questionable. To sum up, a breakthrough discovery is long awaited yet to meet global standards.

\section{CONFLICT OF INTEREST}

The authors have no conflict of interest.

\section{ACKNOWLEDGMENT}

The authors are very grateful to Chandigarh Group of colleges for providing support to write this article.

\section{REFERENCES}

[1]. Wisnicky W. and Cassida L E A manual method for diagnosis of pregnancy in cattle. J.Am. Vet. Med. Assoc, 1948,. 113:451

[2]. Curran S, Pierson R A and Ginther OJ , Ultrasonographic appearance of the bovine conceptus from days 10 through 20. J. Am. Vet. Med. Assoc. 1986, 189:1289-1294

[3]. zemjanis R, Diagnostic and Therapeutic Techniques in Animal Reproduction 2nd Edition, 1970, p57, Baltimore, Williams and Wilkins.

[4]. Thatcher, Uterine-conceptus interactions and reproductive failure in cattle.TheriogenologyVolume 56, Issue 9, 1 December 2001, Pages 1435-1450

[5]. Wolf E, Arnold GJ, Bauersachs S, Beier HM, Blum H, Einspanier R, et al. Embryo-maternal communication in bovine strategies for deciphering a complex cross-talk. Reproduction in Domestic Animals. 2003;38:276-289

[6]. Heap R.B, Hamon M. Oestronesulphate in milk as an indicator of a viable conceptus in cows. British Veterinary Journal. 1979; 135(4):355-363

[7]. XIE, S. Multiple pregnancy-associated glycoproteins are secreted by day 100 ovine placental tissue. Biology of Reproduction, 1997.v.57, n.6, p.1384-1393,

[8]. Nancarrow, CD., Wallace, A.L.C. \& Grewal, A.S. (1981) The early pregnancy factor of sheep and cattle. J. Reprod. Feri. Suppl. 30, 191-199.Pape HC, Marcucio R, Humphrey C, Colnot C, Knobe M, Harvey EJ Trauma-induced inflammation and fracture healing. J Orthop Trauma , 2010, 24: 522-525.

[9]. XIE, S. Multiple pregnancy-associated glycoproteins are secreted by day 100 ovine placental tissue. Biology of Reproduction, 1997.v.57, n.6, p.1384-1393,
[10]. Oliveira JF, Henkes LE, Ashley RL, Purcell SH, Smirnova NP, Veeramachaneni DN, Anthony RV, Hansen TR. Expression of interferon (IFN)-stimulated genes in extrauterine tissues during early pregnancy in sheep is the consequence of endocrine IFNtau release from the uterine vein.Endocrinology. 2008;149:12521259

[11]. Nancarrow, CD., Wallace, A.L.C. \& Grewal, A.S. The early pregnancy factor of sheep and cattle. J. Reprod. Feri. 1981, Suppl. 30, 191-199

[12]. [Zhao, Zhen, Kelle H. Moley, and Ann M. Gronowski. "Diagnostic potential for miRNAs as biomarkers for pregnancyspecific diseases." Clinical biochemistry 46.10-11 (2013): 953960.

[13]. Ioannidis, Jason, and F. Xavier Donadeu. "Circulating miRNA signatures of early pregnancy in cattle." BMC genomics 17.1 (2016): 184

[14].Raposo, Graça, and Willem Stoorvogel. "Extracellular vesicles: exosomes, microvesicles, and friends." J Cell Biol 200.4 (2013): 373-383.

[15].Chen, $\mathrm{Xi}$, et al. "Characterization of microRNAs in serum: a novel class of biomarkers for diagnosis of cancer and other diseases." Cell research 18.10 (2008): 997.

[16].Ncube, H., Duncan, P., Grange, S., Cameron, E. Z., Barnier, F., \& Ganswindt, A. (2011). Pattern of faecal 20-oxopregnane and oestrogen concentrations during pregnancy in wild plains zebra mares. General and comparative endocrinology, 172(3), 358362.

[17].Burns, G., Brooks, K., Wildung, M., Navakanitworakul, R., Christenson, L. K., \& Spencer, T. E. (2014). Extracellular vesicles in luminal fluid of the ovine uterus. PloS one, 9(3), e90913.

[18].Pohler, K. G., et al. "Circulating concentrations of bovine pregnancy-associated glycoproteins and late embryonic mortality in lactating dairy herds." Journal of dairy science 99.2 (2016): 1584-1594

[19]. Fiandanese et al., 2016). Fiandanese, Nadia, et al. "71 CIRCULATING micrornas AS POTENTIAL BIOMARKERS OF EARLY PREGNANCY IN HIGH-PRODUCING DAIRY COWS." Reproduction, Fertility and Development 28.2 (2016): $165-165$.

[20]. Ioannidis, Jason, and F. Xavier Donadeu. "Circulating miRNA signatures of early pregnancy in cattle." BMC genomics 17.1 (2016): 184.

[21].Kizaki K, Kizaki AS, Furusawa T, Takahashi T, Hosoe M, Hashizume K (2013) Differential neutrophil gene expression in early bovine pregnancy.ReprodBiolEndocrinol 11, 6 Kobayashi SD, Voyich JM, Burlak C, DeLeo

[22].Irfan ahmed bhat M.V.Sc theisis, National Dairy research institute Karnal.(2014)

[23]. Shirasuna K, Matsumoto H, Kobayashi E, Nitta A, Haneda S, Matsui M, Kawashima C, Kida K, Shimizu T, Miyamoto A (2012) Up regulation of interferon-stimulated genes and interleukin-10 in peripheral blood immune cells during early pregnancy in dairy cows.J ReprodDev58: 84- 90

[24]. Irfan Ahmad Bhat, Mandheer Kaur, Mohanned Alhussien, Jaya Kumar Sivalingam, SandhyaToki, Satpal Dixit, Shiv Prasad, A.K. Mohanty, A.K. Dang." Changes occurring in the receptors of blood neutrophils during implantation in Sahiwal cows" Indian J. Dairy Sci. 68(3), 2015:241-257.

[25].Hendricks DM." Estrogen concentrations in bovine and porcine tissues J Toxicol Environ Health. 1976 Mar;1(4):617-39 